\title{
REMOTE SENSING OF VOLCANIC ASH AT THE MET OFFICE
}

\author{
F. Marenco*, J. Kent, M. Adam, J. Buxmann, P. Francis and J. Haywood
}

Met Office, Exeter EX1 3PB, United Kingdom; *Email:franco.marenco@metoffice.gov.uk

\begin{abstract}
The eruption of Eyjafjallajökull in 2010 has triggered the rapid development of volcanic ash remote sensing activities at the Met Office. Volcanic ash qualitative and quantitative mapping have been achieved using lidar on board the Facility for Airborne Atmospheric Measurements (FAAM) research aircraft, and using improved satellite retrieval algorithms. After the eruption, a new aircraft facility, the Met Office Civil Contingencies Aircraft (MOCCA), has been set up to enable a rapid response, and a network of ground-based remote sensing sites with lidars and sunphotometers is currently being developed. Thanks to these efforts, the United Kingdom (UK) will be much better equipped to deal with such a crisis, should it happen in the future.
\end{abstract}

\section{INTRODUCTION}

The eruption of Eyjafjallajökull in 2010 has put the Met Office at the centre of public attention, due to its responsibilities as Volcanic Ash Advisory Centre (VAAC). The policy followed by aviation authorities until then had been to avoid flying in any volcanic ash, but it was rapidly updated into a number of concentration thresholds. The need to estimate concentrations has since then occurred for forecasters, and this has triggered advances in terms of research, and improvements of the observing infrastructure.

\section{AIRCRAFT OBSERVATIONS}

In 2010, a detailed dataset of volcanic ash concentrations has been compiled from airborne lidar measurements [1]. The data were collected over the UK and surrounding seas, during six flights of the FAAM research aircraft (Fig. 1). In addition to the remote sensing, in-situ data were collected during plume penetrations, and yielded information on the size-distribution. This information has been exploited to evaluate the ash specific extinction, and hence to convert lidarderived extinction to concentration (Fig. 2).
This dataset has been successfully used for the improvement of dispersion models [see e.g. Ref. 2 and 3] and for the validation of satellite products based on the Infrared Atmospheric Sounding Interferometer (IASI) and the Spinning Enhanced Visible and Infrared Imager (SEVIRI) [see e.g. Ref. 4 and 5]. The volcanic ash was observed to be in patches extending $85-550 \mathrm{~km}$ in the horizontal and $0.5-3 \mathrm{~km}$ in the vertical, with typical concentrations of $300-650 \mu \mathrm{g} / \mathrm{m}^{3}$ (maxima of $\left.800-1900 \mu \mathrm{g} / \mathrm{m}^{3}\right)$. The altitude of the volcanic layers was found between 2 and $8 \mathrm{~km}$.

To be able to face future eruptions, the MOCCA aircraft has been set up (Fig. 1). This Cessna 421, driven by piston engines, carries an $\mathrm{SO}_{2}$ analyser, a three-wavelength nephelometer, a Cloud, Aerosol, and Precipitation Spectrometer (CAPS), and a Leosphere ALS450 backscatter lidar operating at $355 \mathrm{~nm}$.
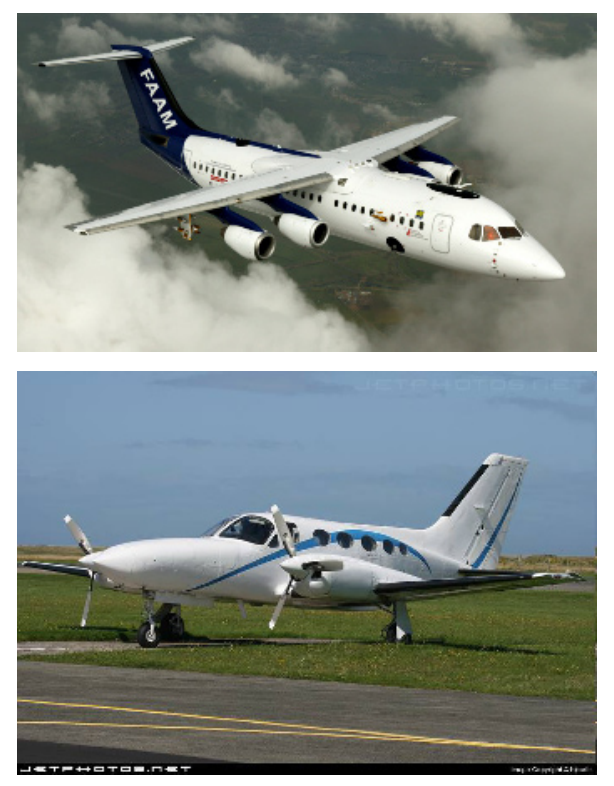

Figure 1. The FAAM (top) and MOCCA (bottom) research aircraft. 

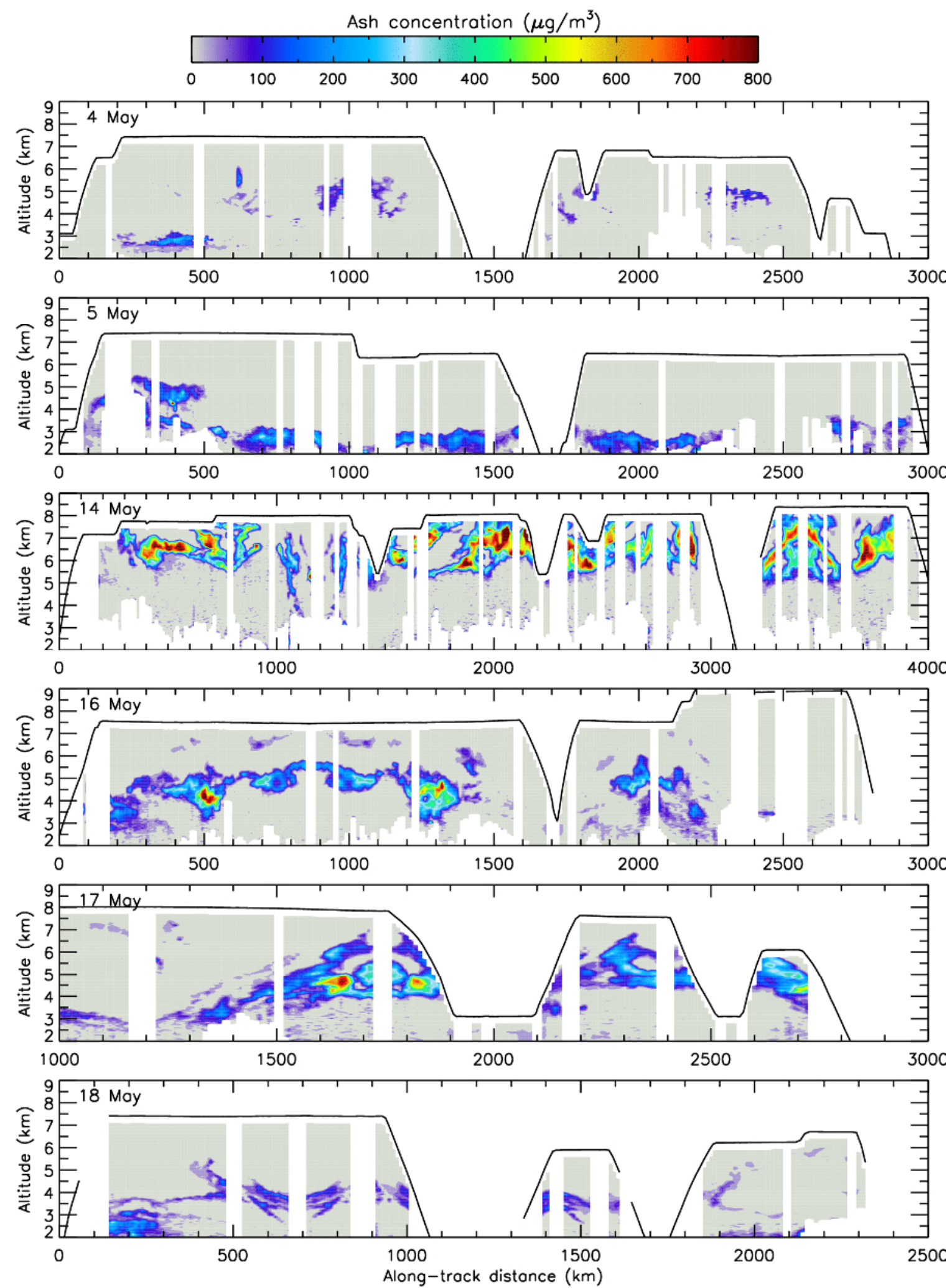

Figure2. Volcanic ash concentration estimated from the airborne lidar observations, for the six research flights. 


\section{QUALITATIVE AND QUANTITATIVE SATELLITE RETRIEVALS}

A robust method to detect volcanic ash, using data from the infrared channels of SEVIRI has been investigated [4]. Moreover, the simultaneous retrieval of quantitative volcanic ash physical properties using a one-dimensional variational analysis framework has been developed. Sensitivity experiments have shown that the retrieved quantities are strongly dependent on the choice of ash refractive index. The retrievals compare well with the airborne lidar results (see Fig. 3).

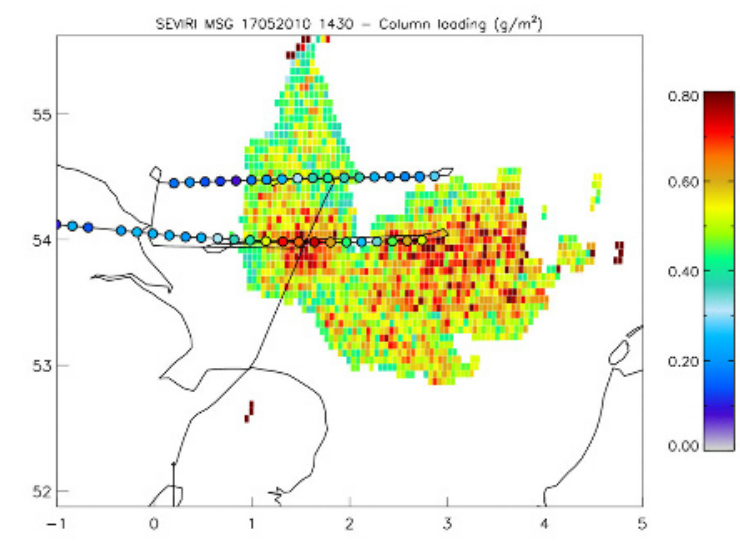

Figure 3. Volcanic ash column loading over the North Sea, determined from Meteosat products for 17/5/2010 at 14:30. Overlaid is the flight track of the FAAM aircraft, and the coloured circles represent the column loadings determined with the aircraft lidar.

Moreover, simulated satellite imagery is being produced every time the Numerical Atmosphericdispersion Modelling Environment (NAME) dispersion model runs [6]. The simulated imagery (see Fig. 4) permits likewise comparison with the actual imagery, and is a useful tool for assessing the quality of the forecast and for understanding how the ash layer properties affect the imagery itself.

\section{IMPROVED GROUND-BASED REMOTE SENSING NETWORKS}

For the purpose of detecting volcanic ash plumes, nine ground-based sites distributed over the UK will be equipped with single-wavelength Raymetrics LR111-D300 Raman/depolarization
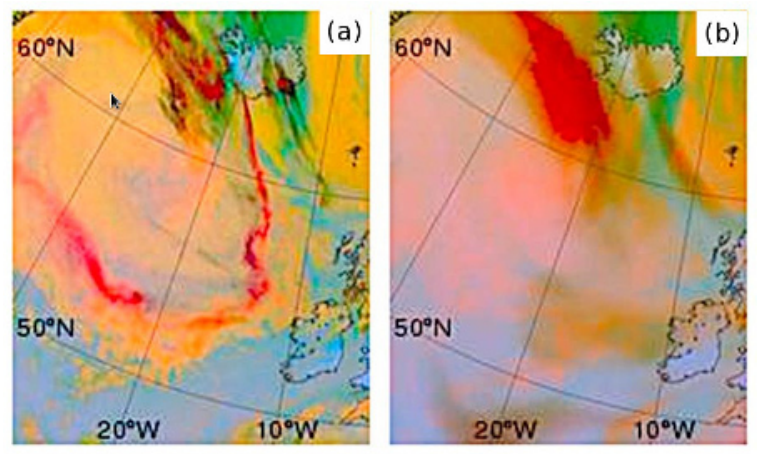

Figure 4. (a) "Dust RGB" product from SEVIRI/MSG for 9/5/2010 at 12:00 and (b) imagery simulated from the NAME dispersion model output for the same time. Courtesy of Sarah Millington.

lidar systems operating at $355 \mathrm{~nm}$ and 8wavelength CIMEL CE318 NE DPS9 sunphotometers (Fig. 5). In addition, one mobile unit will be also available, having the same

equipment. Currently, one fixed site and the mobile unit are installed. These developments represent a great improvement of coverage over the country for ground-based remote sensing observations, and are complemented by the observations of the operational ceilometers network [7].

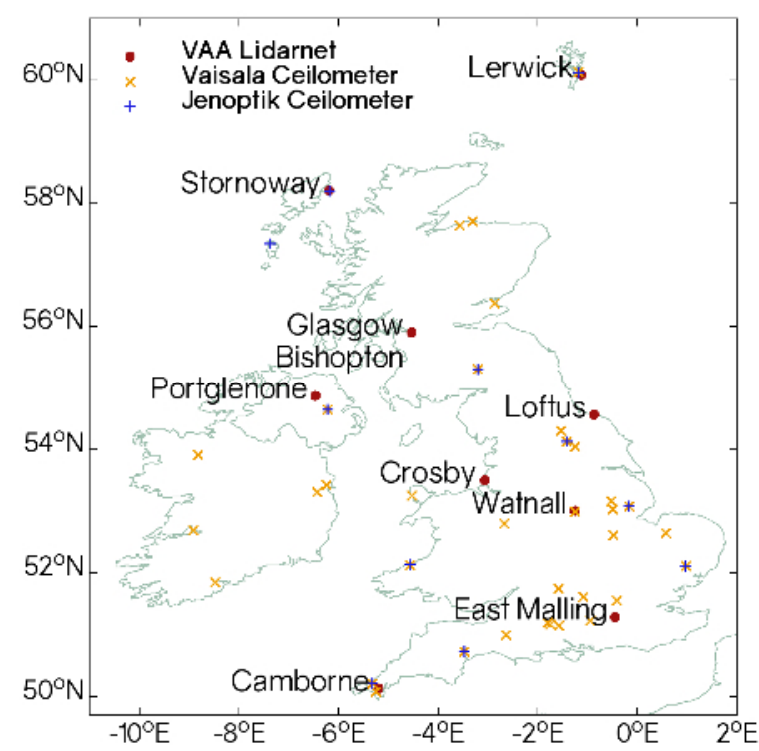

Figure 5. The future volcanic ash lidar and sunphotometer network, and the operational ceilometers network. 


\section{ACKNOWLEDGEMENTS}

Airborne data was obtained using the BAe-146 Atmospheric Research Aircraft flown by Directflight Ltd. and managed by the Facility for Airborne Atmospheric Measurements (FAAM), which a joint entity of the Natural Environment Research Council (NERC) and the Met Office. The MOCCA aircraft and the ground-based lidar network are funded by the Civil Aviation Authority and the Department for Transport.

\section{REFERENCES}

[1] Marenco et al, Airborne lidar observations of the 2010 Eyjafjallajökull volcanic ash plume, JGR 2011.

[2] Webster et al, Operational prediction of ash concentrations in the distal volcanic cloud from the 2010 Eyjafjallajökull eruption, JGR 2012.

[3] Kristiansen et al, Performance assessment of a volcanic ash transport model mini-ensemble used for inverse modeling of the 2010 Eyjafjallajökull eruption, JGR 2012.

[4] Francis et al, Retrieval of physical properties of volcanic ash using Meteosat: A case study from the 2010 Eyjafjallajökull eruption, JGR 2012.

[5] Newman et al, A case study of observations of volcanic ash from the Eyjafjallajökull eruption: 2. Airborne and satellite radiative measurements, JGR 2012.

[6] Millington et al, Simulated volcanic ash imagery: A method to compare NAME ash concentration forecasts with SEVIRI imagery for the Eyjafjallajökull eruption in 2010, JGR 2012.

[7]Adam et al, From operational ceilometer network to operational lidar network, 27th ILRC Coordinated lidar networks and applications, 2015. 